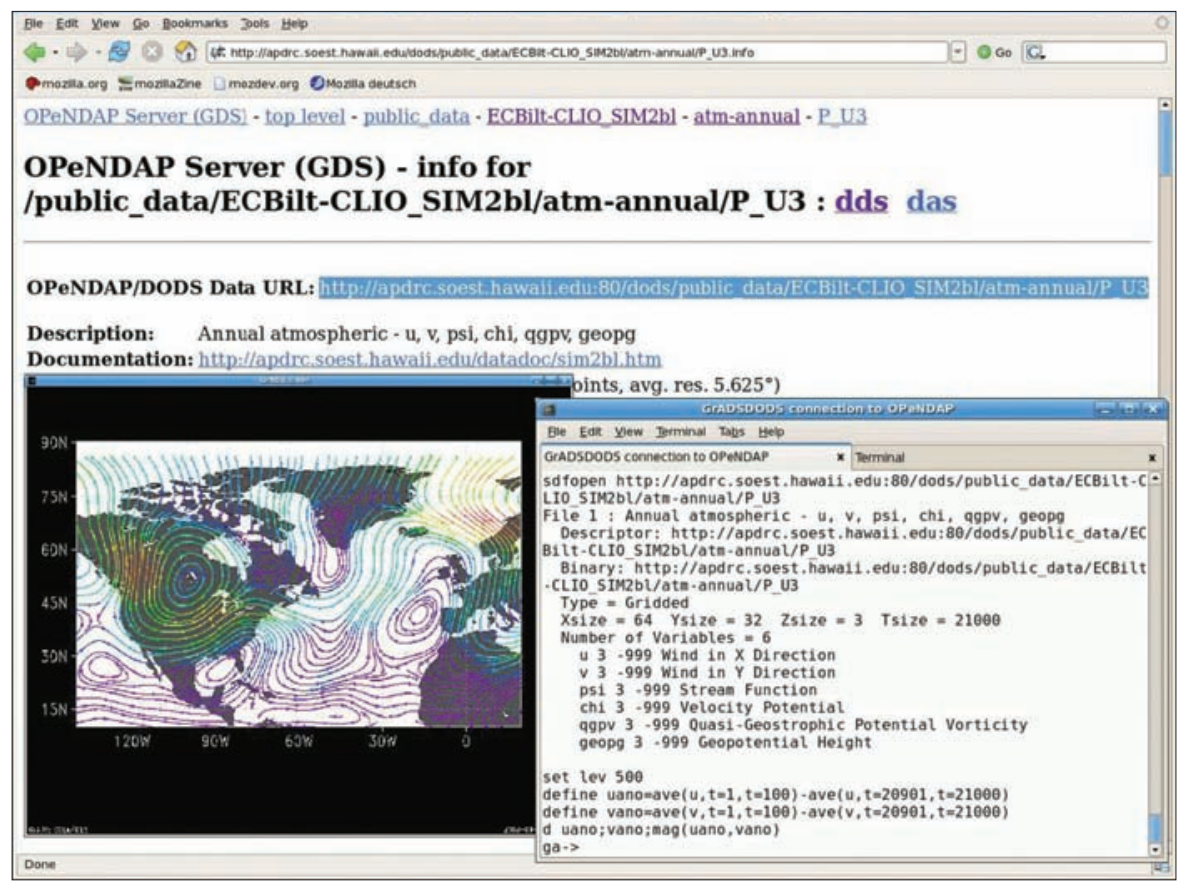

Figure 2: Screen shot of the direct integration of the atmospheric model data into GrADS through the OPENDAP server. Shown are the differences in the 500-hPa wind field (streamlines) between LGM and pre-industrial times.

In comparison, the OPeNDAP server allows researchers to work directly with the data within their data visualization/manipulation tools (e.g., GrADS, Ferret or MATLAB), provided their software version supports the OpeNDAP access of remote datasets.

When selecting OPeNDAP, the APDRC will guide the user through the oceanic/ atmospheric datasets to the sub-categories. By clicking on "info", the user can obtain the necessary URL and additional information on the variables in the dataset (see screen shot Fig. 2). The URL is needed to open a connection from the research- data sources will allow a deeper insight into the underlying physical mechanisms behind glacial-interglacial cycles and millennial-scale variability.

\section{Note}

APDRC: http://apdrc.soest.hawaii.edu/

Data portal to the $21 \mathrm{kyr}$ paleo-simulation: http://apdrc.soest.hawaii.edu/las/servlets/ dataset?dset=APDRC\%20PublicAccess $\% 20$ Products/ECBilt-CLIO\%20SIM2bl

Project page with description and tutorial examples: http://apdrc.soest.hawaii.edu/projects/ paleomodeling/index.html

\section{Acknowledgements}

This research was supported by NSF (grant ATM06-28393). Additional support was provided by the Japan Agency for Marine-Earth Science and Technology (JAMSTEC), NASA (grant NNX07AG53G), and NOAA (grant NA17RJ1230) through their sponsorship of research activities at the International Pacific Research Center.

\section{References}

Goosse, H. and Fichefet, T., 1999: Importance of ice-ocean interactions for the global ocean circulation: A model study, Journal of Geophysical Research,104(C10): 23337-23356, doi:10.1029/1999JC900215. remote data.

We hope that this easy web-access to paleo-model data will stimulate new model-data intercomparison studies focusing on the last glacial termination and the Holocene. Unrestricted access to transient paleoclimate simulations will facilitate the climatic interpretation of geobiochemical information from marine and terrestrial proxy archives. Independent validation of model simulations with proxy records will further help to test the robustness of the model results. The combination of both

Opsteegh, J.D., Haarsma, R.J., Selten, F.M. and Kattenberg, A. 1998: ECBILT: A dynamic alternative to mixed boundary conditions in ocean models, Tellus, 50A(3): 348-367, doi:10.1034/j.1600-0870.1998.t01-1-00007.

Timm, 0., and Timmermann, A. 2007: Simulation of the last 21,000 years using accelerated transient boundary conditions, Journal of Climate, 20(17): 4377-4401. doi: 10.1175/JCLI4237.1

Timm, O., Timmermann, A., Abe-Ouchi, A., Saito, F. and Segawa, T., 2008: On the definition of seasons in paleoclimate simulations with orbital forcing, Paleoceanography, 23: PA2221, doi:10.1029/2007PA001461.

Timmermann, A., Timm 0., Stott, L, and Menviel, L, 2008: The roles of $\mathrm{CO}_{2}$ and orbital forcing in driving southern hemispheric temperature variations during the last 21,000 years, accepted in Journal of Climate.

\title{
High- to low-latitude teleconnections during glacial terminations associated with ENSO-like variability
}

Leopoldo D. Pena ${ }^{1,2}$ and Isabel CaCho $^{1}$

'Department of Stratigraphy, Paleontology and Marine Geosciences, University of Barcelona, Spain;

${ }^{2}$ Now at Lamont Doherty Earth Observatory of Columbia University, Palisades, USA; leopoldo@ldeo.columbia.edu

\section{Long-term changes in ENSO-like dynamics during deglaciations are linked to southern high-latitude regions through atmospheric and oceanic teleconnection mechanisms.}

Many studies have recognized that EI Niño-Southern Oscillation (ENSO) variability influences climate patterns around the globe (Cane, 1998; Federov and Philander, 2000). This has led to considerable efforts to unravel the history of ENSO and establish its role in past global changes. An increasing number of studies point towards tropical regions, and more particularly to ENSO-like variability (i.e., long-term ENSO variability), as one of the missing pieces in the cause of the Pleistocene glacialinterglacial climate variability. However, evidence for the nature of long-term ENSO variability is still conflicting. In particular, periods of global deglaciation have not shown prevailing El Niño-like or La Niñalike conditions in the tropical Pacific (Beaufort et al., 2001; Koutavas et al., 2002, 2006; Stott et al., 2002). Discrepant evidence may result from the inherently limited temporal resolution and fragmentary nature of the different proxy records. Modeling studies have provided a framework for the ENSO-like variability associated with orbital variations (Cane, 1998, 2004; Clement et al., 1999, 2000; Zebiak and Cane, 1987) and highlight the potential role of orbital dynamics in forcing the ENSO-like variability, through the modulation of the annual cycle of sea surface temperature, atmospheric convection and inter-tropical convergence zone migration in the eastern tropical Pacific (ETP). Although their conceptual basis is sound, tropical climate models still lack more accurate representations of high-low latitude teleconnection mechanisms, partially due to a limited understanding of the processes involved. These limitations highlight the importance of paleo-records to provide informa- 
tion on the processes linking ENSO-like variability and high-latitude climate.

\section{Orbital forcing of ENSO-like variability}

New high-resolution paleorecords from the ETP were generated from a marine sediment core (ODP Site 1240) (Fig. 1) to reconstruct long-term ENSO-like variability and its linkage to orbital forcing (Pena et al., 2008). Past thermocline seawater properties were reconstructed by analyzing both stable isotopes $\left(\delta^{18} \mathrm{O}, \delta^{13} \mathrm{C}\right)$ and paleotemperatures $(\mathrm{Mg} / \mathrm{Ca})$ in the calcite shells of the thermocline dwelling foraminifer species (N. dutertrei). This allowed the calculation of seawater $\delta^{18} \mathrm{O}$ in the deep thermocline $\left(D T-\delta^{18} \mathrm{O}_{\text {sw }}\right.$ ) as an indicator of local salinity changes (Fig. 1). Saltier waters at the thermocline are associated with an intensified Equatorial Undercurrent (EUC) and strengthened upwelling in the ETP (Pena et al., 2008). Thus, more positive values of DT- $\delta^{18} \mathrm{O}_{\text {sw }}$ indicate saltier waters at the thermocline, which are interpreted as stronger EUC and enhanced upwelling conditions. Accordingly, periods characterized by positive DT- $\delta^{18} \mathrm{O}_{s w}$ excursions (stronger EUC) are indicative of enhanced La Niña-like conditions in the ETP.

The DT- $\delta^{18} \mathrm{O}_{s \mathrm{w}}$ record displays salinity variations of thermocline waters (and hence upwelling intensity) that closely match the fluctuations in orbital precession (Fig. 1). Low precession periods are associated with enhanced upwelling in the ETP (La Niña-like conditions), high precession periods with reduced upwelling (Pena et al., 2008). This observation is in agreement with model simulations, where the shift in the timing of the perihelium (point on orbit nearest to the sun) from boreal winters (high precession index) to boreal summers (low precession index) reinforces the seasonally asymmetric wind field above the equator (Clement et al., 1999). This strengthens the E-W asymmetry in the atmosphere (enhancing the Walker circulation) and eventually in the ocean, promoting the development of La Niña-like conditions (Clement et al., 1999).

\section{Teleconnection mechanisms}

Some low precession periods that would be expected to show DT- $\delta^{18} \mathrm{O}_{s w}$ maxima deviate from this precessional pattern (Fig. 1). These periods coincide with low obliquity conditions. In contrast, the largest DT- $\delta^{18} \mathrm{O}_{s w}$ excursions associated with an intensified La Niña-like state in the ETP take place during glacial terminations with concurrent low precession and high obliquity conditions (Fig. 1). An obliquity signature has previously been described

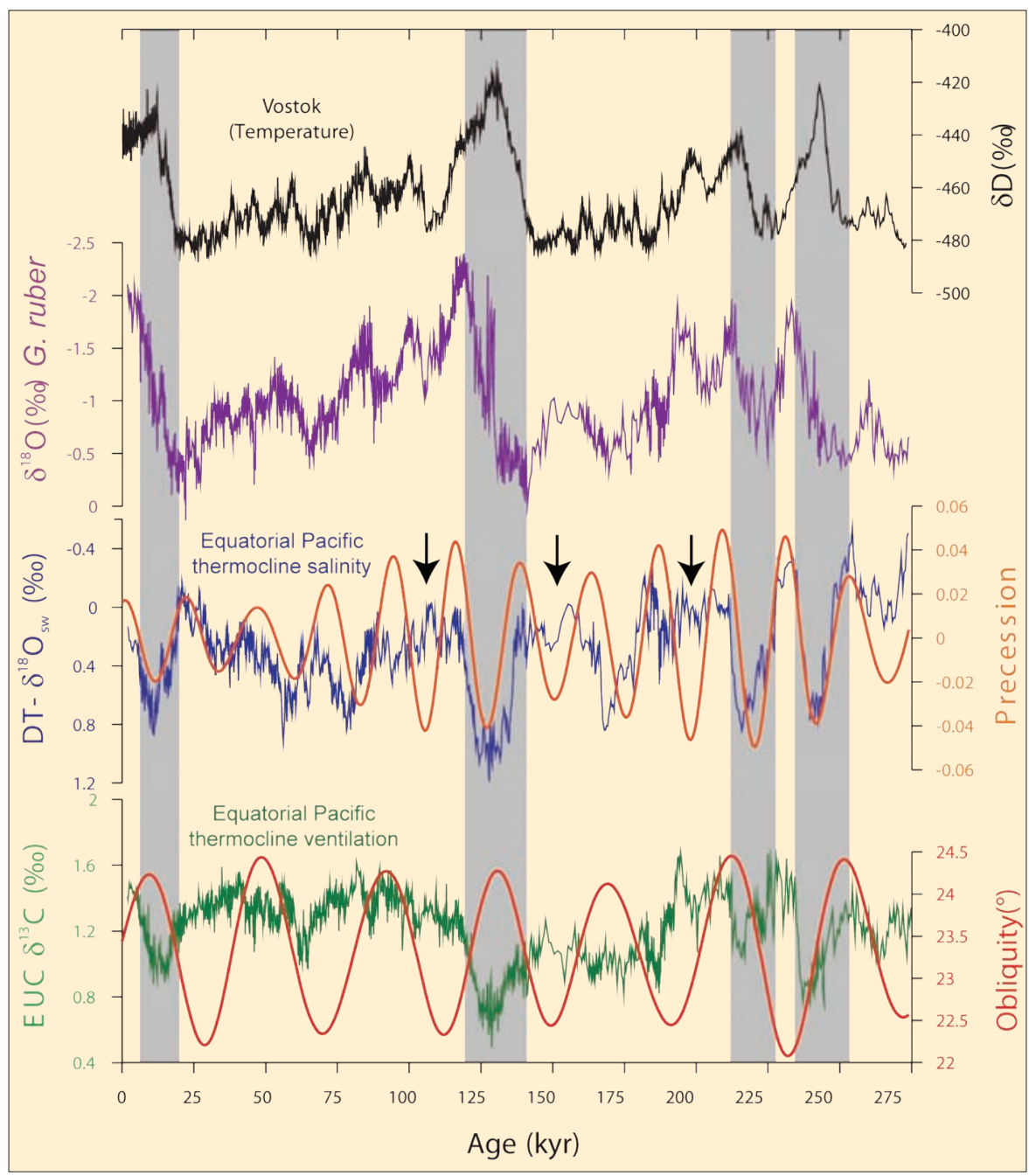

Figure 1: East tropical Pacific ODP Site 1240 records ( $0^{\circ} 01.31^{\prime} \mathrm{N}, 86^{\circ} 27.76^{\prime} \mathrm{W} ; 2921 \mathrm{~m}$ water depth); Antarctic Vostok deuterium ( $\delta D$; black) (Petit et al., 1997); Site $1240 \mathrm{G}$. ruber $\delta^{18} \mathrm{O}$ record for stratigraphic reference (purple; Pena et al., 2008); calculated deep thermocline seawater $\delta^{18} \mathrm{O}\left(\mathrm{DT}-\delta^{18} \mathrm{O}\right.$; blue), after removal of global ice volume effect, as a proxy for relative salinity changes in the ETP thermocline; orbital precession index (orange); $\delta^{13} \mathrm{Crecord}$ measured on N. dutertrei and associated with the Equatorial Undercurrent (EUC) (green); orbital obliquity index (red). Vertical shadowed bars mark periods of intense DT- $\delta^{18} \mathrm{O}$ and $\delta^{13} \mathrm{C}$ excursions coinciding with low precession and high obliquity. Black arrows indicate periods where $D T-\delta^{S W} \mathrm{O}_{s w}$ values deviate from the precessional pattern.

in tropical Pacific records (Lea et al., 2000) and is significantly depicted in the frequency spectrum analyses of the ETP thermocline (Pena et al., 2008). The influence of obliquity on the ENSO-like variability is puzzling because the insolation forcing due to obliquity changes is rather small at low latitudes $\left(<3 \mathrm{Wm}^{-2}\right)$. Therefore, it is unlikely that the $41-k y r$ periodicity in tropical records arises as a direct climatic response to obliquity-driven insolation changes (Lee and Poulsen, 2005).

It is more plausible that the obliquity influence is propagated from high latitudes (where the obliquity-related insolation changes are stronger) to low latitudes by means of atmospheric teleconnections (Chiang and Lintner, 2005), or via the ocean through equatorward advection of sub-surface waters (Bostock et al., 2004; Lee and Poulsen, 2005). Intense negative $\delta^{13} \mathrm{C}$ excursions in the thermocline waters of the ETP (Figs. 1 and 2) during glacial terminations are a persistent feature in numerous tropical records, and have previously been explained as a signal advect- ed from the Southern Ocean (Ninnemann and Charles, 1997; Shackleton et al., 1983; Spero and Lea, 2002). At Site 1240, these negative $\delta^{13} \mathrm{C}$ excursions occur in parallel with the enhancement of La Niña-like conditions (high DT- $\delta^{18} \mathrm{O}_{s w}$ ) during glacial terminations (Fig. 2). Moreover, these isotopic excursions are synchronous with the onset of the deglacial atmospheric $\mathrm{pCO}_{2}$ increase recorded in Antarctic ice cores (Pena et al., 2008; Spero and Lea, 2002). The low $\delta{ }^{13} \mathrm{C}$ signal is due to the resumption of the circum-Antarctic upwelling of "old" waters that are eventually incorporated into intermediate water masses (most likely subantarctic mode water) and advected into the tropical thermocline through the "oceanic tunnel" (Pena et al., 2008; Spero and Lea, 2002). This scenario is supported by the close match between decreasing sea salt sodium fluxes in Antarctic ice cores (ssNa flux), an indicator of Antarctic sea ice extension (Wolff et al., 2006), and the ETP $\delta^{13} \mathrm{C}$ minimum during the deglaciation (Fig. 2). During this period, high obliquity resulted in increased 
summer insolation at high latitudes and therefore in a decrease in sea ice around Antarctica. With the retreat of sea ice, a resumption of Southern Ocean upwelling could be driven by a southward shift and/ or an intensification of the westerly winds around Antarctica, a feature supported by different model studies (Rojas et al., 2008; Toggweiler et al., 2006). The southward shift of the westerlies could also be induced by the establishment of La Niñalike conditions in the ETP (Toggweiler, 1999; Toggweiler et al., 2006), an observation that has been recently confirmed by means of meteorological satellite information during El Niño and La Niña periods (Pena et al., 2008; Yuan, 2004).

\section{The last deglaciation scenario}

The combination of low precession and high obliquity conditions during the last deglaciation resulted in a particular sequence of events: Perihelium during boreal summer (low precession) enhances the seasonal wind field divergence and temperature gradients in the ETP shifting the system towards La Niña-like conditions. Thus, the establishment of La Niña-like

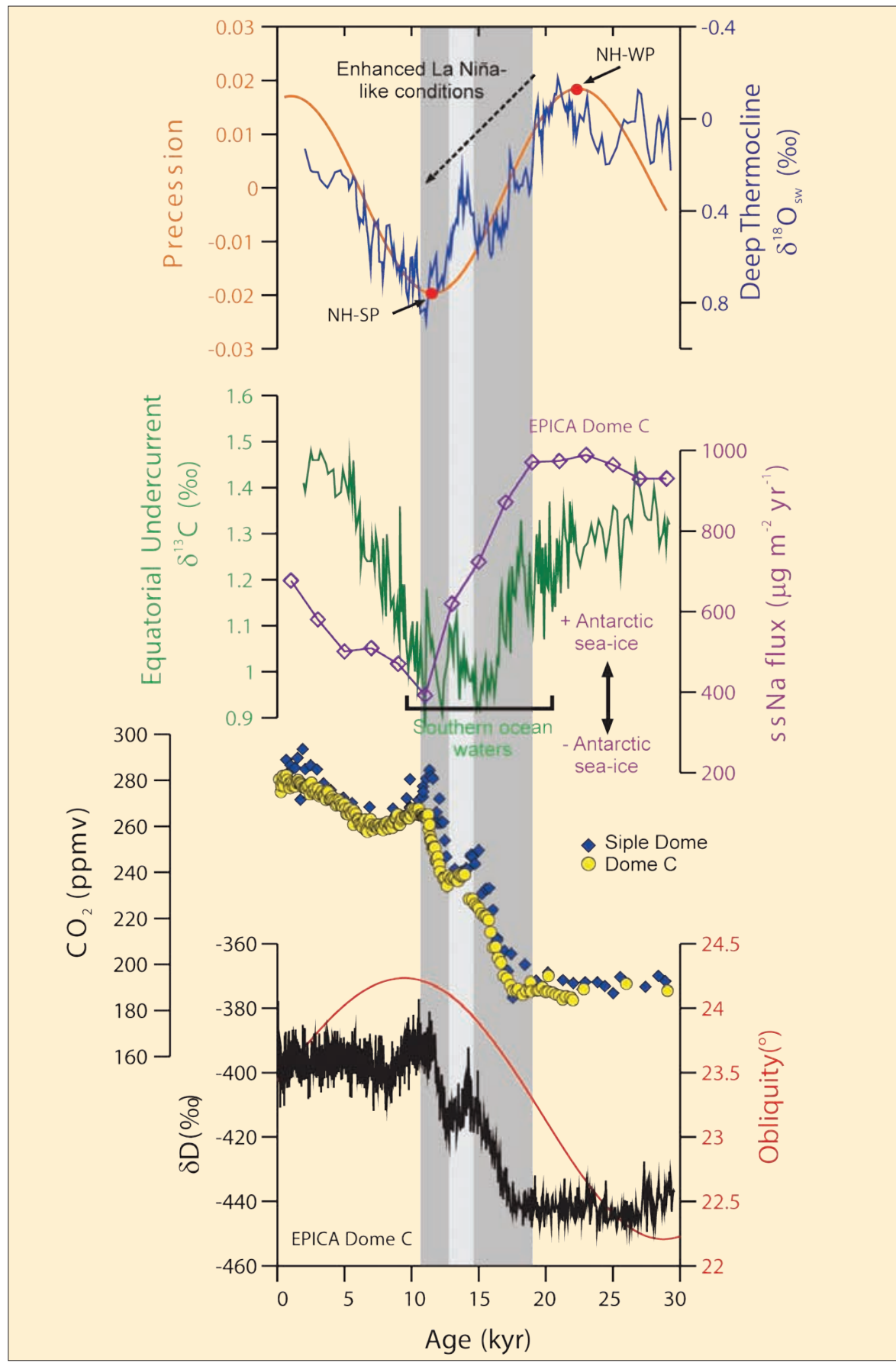

Figure 2: Detail of the last $30 \mathrm{kyr}$ of Deep Thermocline $\delta^{18} \mathrm{O}_{\text {sw }}$ (blue) compared to the thermocline $\delta^{13} \mathrm{C}$ (green) at Site 1240 (Pena et al., 2008). The orbital precession index (orange) is plotted for reference. NH-WP = Northern Hemisphere Winter Perihelium; NH-SP = Northern Hemisphere Summer Perihelium. Also included is the sea salt sodium flux record (purple), as an indicator of Antarctic sea ice extension (Wolffet al., 2006). Antarctic $\mathrm{CO}_{2}$ records from Siple Dome (blue diamonds) (Ahn et al., 2004) and EPICA Dome C (yellow circles) (Monnin et al., 2001) have been plotted for reference, as well as the Dome C deuterium ( $\delta D$; black) (Jouzel et al., 2007) and the obliquity (red). Dark gray bar indicates the period of enhanced La Niña-like conditions in the ETP, light gray bar highlights a reversed interval of weaker La Niña-like conditions coincident with a plateau in the Antarctic $\mathrm{CO}_{2}$ record and the Antarctic Cold Reversal period.

conditions induces a southward shift of the westerlies in the southern hemisphere. In parallel, high obliquity conditions increase summer insolation at high latitudes and cause Antarctic sea ice retreat. Eventually, the combination of a southward shift of the westerlies and poleward retreat of sea ice favors the intensification of circumAntarctic upwelling, which advects more "old" waters to the surface that are ultimately incorporated into intermediate water masses and propagated through "oceanic tunnel" advection towards tropical thermoclines.

\section{Acknowledgements}

We acknowledge support from the Gary Comer Science and Education Foundation, Natural Environmental Research Council, UK-Ocean Drilling Program (ODP), "Ramón y Cajal" program (MEC-Spain) and the Catalan Government. Samples were provided by ODP (sponsored by the U.S. National Science Foundation and participating countries under management of Joint Oceanographic Institutions).

\section{Note}

All presented data will be available from the NOAA Paleoclimatology website at www.ncdc. noaa.gov/paleo/paleo.html

\section{References}

Clement, A.C., Seager, R. and Cane, M.A., 1999: Orbital controls on the El Niño/Southern Oscillation and the tropical climate, Paleoceanography, 14: 441-456.

Koutavas, A., Lynch-Stieglitz, J., Marchitto, T.M. and Sachs, J.P., 2002: El Niño-Like Pattern in Ice Age Tropical Pacific Sea Surface Temperature, Science, 297: 226-230.

Pena, L.D., Cacho, I., Ferretti, P. and Hall, M.A., 2008: El Niño-Southern Oscillation-like variability during glacial terminations and interlatitudinal teleconnections, Paleoceanography, 23: PA3101, doi:10.129/2008PA001620

Spero, H.J. and Lea, D.W., 2002: The Cause of Carbon Isotope Minimum Events on Glacial Terminations, Science, 296: 522-525.

Wolff, E.W., et al., 2006: Southern Ocean sea-ice extent, productivity and iron flux over the past eight glacial cycles, Nature, 440 : 491-496.

For full references please consult:

www.pages-igbp.org/products/newsletters/ref2009_1.html 